\title{
Hairy cell sarcoma
}

\author{
JONATHAN H. Y. WAXMAN \\ B.Sc., M.B., B.S., M.R.C.P. \\ Department of Medical Oncology, St Bartholomew's Hospital, London ECIA 7BE
}

\begin{abstract}
Summary
The first case of a hairy cell sarcoma is presented. Subsequent to surgical resection and post-operative radiotherapy the patient has survived two years without systemic evidence of hairy cell leukaemia.
\end{abstract}

KEY WORDS: hairy cell sarcoma, leukaemia, reticuloendotheliosis.

\section{Introduction}

Extramedullary solid tumours may precede systemic evidence of leukaemia. They are previously unreported in hairy cell leukaemia.

\section{Case report}

A 39-year-old coal merchant presented to his family practitioner with a seven month history of swelling of the left side of his face. He was referred to hospital where a left parotid mass was noted. All routine haematological and biochemical investigations were normal. A needle biopsy of the parotid mass, showed, on light microscopy using mercury based fixation, the presence of cells whose appearance was suggestive of hairy cell leukaemia. The cells failed to stain with acid phosphatase, non-specific esterase, chloroacetate esterase, periodic acid schiff and unna pappenheim/alcian blue. Bone marrow aspiration and trephine showed no evidence of leukaemia. Computed tomography of the chest and abdomen revealed no other deposits. The patient proceeded to surgery, where a mass infiltrating the superficial part of the parotid gland was excised. Electron microscopy showed it to be composed of typical hairy cells (Fig. 1). Post-operatively the parotid area and the whole of the lymphatic drainage of both sides of the neck from basicranium to clavicles was irradiated, using a radiocobalt unit. Lateral fields were applied and tissue compensators used. A tumour dose was delivered of $3500 \mathrm{cGy}$ in 25 fractions over 29 days. Two years after presentation the patient is well without systemic evidence of hairy cell leukaemia.

\section{Discussion}

Extramedullary leukaemia was first reported im 1811 when Burns described an ocular chloroma These large solid deposits should be distinguisheg from microscopic metastatic leukaemia which is common and observed in over $80 \%$ of patients at post-mortem (Hustu and Aur, 1978). Common site of infiltration include lymph nodes, spleen, testes and the central nervous system (Viadara, Bross anst Pickren, 1978). Extramedullary solid tumours ar reported as occurring in $8 \%$ of acute myeloid and 4 of patients with chronic myeloid leukaemia (Liu et al., 1973). They are collectively termed granulocgtits sarcoma. When green they are described as chlor of mata, when colourless, myeloblastomata (Muss Q Moloney, 1973). The pigment may be a function of the presence of a porphyrin-containing enzym $\bar{E}$ myeloperoxidase (Schulz and Rosenthal, 1959ఖ Their distribution is widespread, most commonly i bone (Liu et al., 1973), rarely in breast (Blackwell 1973), skin (Wiernick and Serpick, 1970), centra nervous system (Hurwitz, Sutherland and Walket 1970), uterus (Hartford, 1968) and ovary (Hinkampe Evanston and Szanto, 1958). Occurring as an isolated finding, they invariably herald systemic leukaemi and the latency period may range up to two yearis (Mason, Demanee and Margolis, 1973).

Leukaemic reticuloendotheliosis or hairy cell lew kaemia was first described in 1958 by Bouroncle Wiseman and Doar. The diagnosis is established bo the presence of the characteristic 'hairy cell', best visualized by electron microscopy (Katovsky et at 1974). The disease is rare, exhibits a male prepondes ance, and has a variably benign course, with a meaศ survival time of 6 years (Bouroncle, 1979). Treatmenty is controversial, and the choice may include splenect tomy, steroids, chemotherapy and splenic irradiation (Bouroncle, 1979; Catovsky et al., 1974; Davis et ato 1976). Infection is a common complication, and the most frequent cause of death (Bouroncle, 1979).

Extra medullary hairy cell sarcoma has not been previously reported. Its outcome is awaited in this patient. 


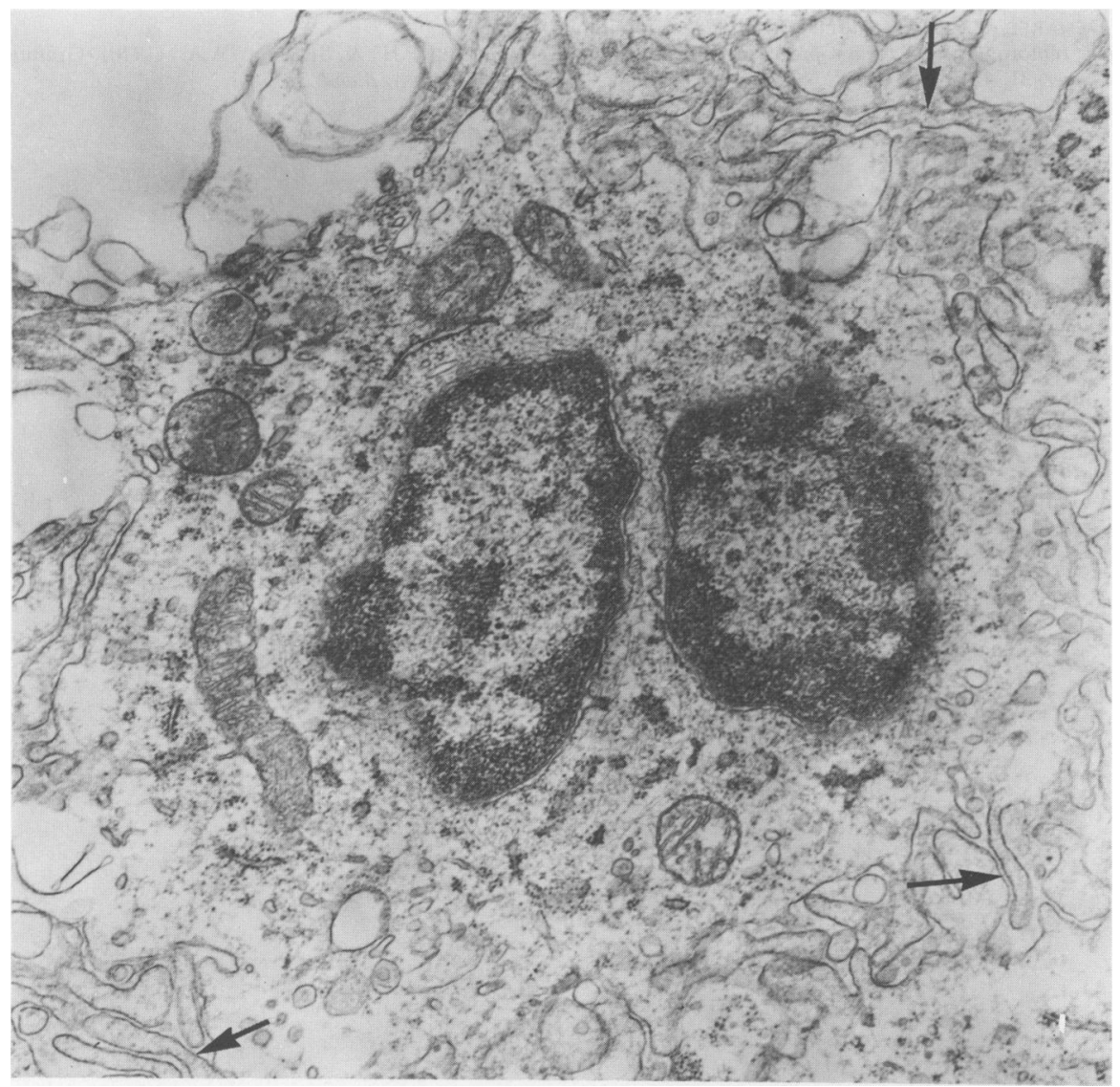

FiG. 1. Electron micrograph. Arrows indicate intercellular hair projections.

\section{Acknowledgments}

Mrs Jo Barton kindly typed the manuscript. Thanks are due to Professor J. S. Malpas and Dr T. A. Lister of the Department of Medical Oncology, Dr D. Levison and Dr A. G. Stansfeld of the Department of Histopathology, Dr J. Amess of the Department of Haematology, and Professor A. E. Jones of the Department of Radiotherapy of St Bartholomew's Hospital.

\section{References}

BlACKWELL, B. (1963) Acute leukaemia presenting as a lump in the breast. British Journal of Surgery, 50, 759.

BouronCle, B.A., WiSEMAN, B.K. \& DOAR, C. (1958) Leukaemic reticuloendotheliosis. Blood, 13, 609.

BoURONCLE, B.A. (1979) Leukaemic reticuloendotheliosis (Hairy cell leukaemia). Blood, 53, 412.
BURNS, A. (1823) In: Observations on the surgical anatomy of the head and neck (Ed by Lucas, F. Jr. \& Cook, E.J.) p. 386, Cushing \& Jewett, Baltimore.

Catovsky, D., Petit, J.E., Galton, D.A.G., Spiers, A.S.D. \& HARRISON, C.V. (1974) Leukaemic reticuloendotheliosis (Hairy cell leukaemia): a distinct clinico-pathological entity. British Journal of Haematology, 26, 9.

Davis, T.E., Waterbury, L., Abeloff, M. \& Burke, P.J. (1976) Leukaemic reticuloendotheliosis, Archives of Internal Medicine, 136, 620.

HARTFORD, C.E. (1968) Bleeding from the uterus caused by a chloroma. Obstetrics and Gynecology, 31, 166.

Hinkamp, J.F.. Evanston, I. \& Szanto, P.B. (1958) Chloroma of the ovary. American Journal of Obstetrics and Gynecology, 78, 812. HURWITZ, B.S., SUTHERLAND, J.C. \& WALKER, M.D. (1970) Central nervous system chloromas preceding acute leukaemia by one year. Neurology, 20, 771. 
Hustu, H.O. \& AUR, R.J.A. 1978) Extramedullary leukaemia. Clinics in Haematology, 7, 313.

Liv, P.I., Ishimaru, T., McGregor, D., Okada, H. \& Steer, A. (1973) Autopsy study of granulocytic sarcoma (chloroma) in patients with myelogenous leukaemia, Hiroshima Nagasaki 1949-1969. Cancer, 31, 948.

Mason, T.E., Demaree, R.S. \& Margolis, C.I. (1973) Granulocytic sarcoma (chloroma) two years preceding myelogenous leukaemia. Cancer, 31, 423.
Muss, H.B. \& Molony, W.C. (1973) Chloroma and other myel lastic tumours. Blood, 42, 721.

SCHULTZ, J. \& Rosenthal, S. (1959) Iron (II) inactivation. myeloperoxidase. Journal of Biological Chemistry, 234, 2486. $\Rightarrow$ Viadara, E., Bross, I.D.J. \& Pickren, J.W. (1978) An autopgry study of the metastatic patterns of human leukaemia. Oncoley, $35,87$.

WIERNIK P.H. \& SERPICK, A.A. (1970) Granulocytic sarcom (chloroma). Blood, 35, 361 .

(Accepted 1 June 1982) 